\title{
THE EFFECT OF CORTICAL LESIONS ON THE ELECTROMYOGRAPHIC RESPONSE TO JOINT DISPLACEMENT IN THE SQUIRREL MONKEY FORELIMB ${ }^{1}$
}

\author{
F. A. LENZ, W. G. TATTON, ${ }^{2} \Lambda$ ND R. R. TASKER \\ Playfair Neuroscience Unit and Division of Neurosurgery, University of Toronto, Toronto, Canada
}

Received July 29, 1982; Revised October 29, 1982; Accepted November 5, 1982

\begin{abstract}
The extent of participation of supraspinal structures in the generation of the long latency (M2) electromyographic (EMG) response to imposed joint displacement may be reflected in the effect of lesions of the central nervous system. M2 activity has been reported in a variety of studies to be either present or absent following supraspinal lesions. Since other studies have shown different characteristics of long latency activity in proximal as compared to distal upper limb muscles in primates, the present experiments were conducted to determine the effect of motor cortical (area 4) lesions on reflex activity generated in a proximal versus a distal upper limb muscle.

Chronic experiments were performed on squirrel monkeys with unilateral lesions of the forelimb motor cortex (area 4) which was mapped with the aid of electrical stimulation. Input-output relationships were determined between torque motor-imposed joint rotation and the EMG response in the stretched muscles (flexor digitorum profundus (FDP) and short head of biceps (SHB)). The EMG responses were reported as a percentage of maximum EMG output and controlled for base line EMG level. The "gain" (slope of EMG response versus torque load) for FDP M2 activity was markedly decreased in the limb contralateral to the area 4 lesion as compared to the opposite limb. This decrease was independent of base line EMG levels. In SHB, early latency (M1) EMG activity was significantly increased, but M2 activity appeared unaffected on the side contralateral to the lesion.

The results demonstrate that the central and peripheral mechanisms generating M2 activity in FDP differ from those in SHB in terms of motor cortical dependency.
\end{abstract}

The electromyographic (EMG) response to joint displacement usually consists of at least two bursts of EMG activity, an early peak (M1) at approximately tendon tap reflex latencies, followed by a longer latency peak of activity (M2) ('Tatton et al., 1975; Lenz et al., 1983). There are a number of different proposals as to the central and/or peripheral mechanisms responsible for the long latency EMG activity. Peripherally, segmentation of the EMG activity could be produced by repetitive activation of $1 \mathrm{~A}$ afferent activity acting through a single spinal reflex pathway (Hagbarth et al., 1981), sequential activation of different afferent populations (Stauffer et al., 1976; Bawa and Tatton, 1979), or reafferent activation

\footnotetext{
${ }^{1}$ Supported by The Multiple Sclerosis Society of Canada, The Ontario Heart Foundation Grant Str-T-2, The Toronto General Hospital Foundation, and Medical Research Council of Canada Grant MA 5218. F. A. L. was a Medical Research Council of Canada Fellow.

${ }^{2}$ To whom correspondence should be addressed at Playfair Neuroscience Unit, Toronto Western Hospital, 399 Buthurst St., Toronto, Ontario, Canada, M5T 2S8.
}

of gamma motoneurons (Appelberg et al., 1977). However, most attention has been focused on central mechanisms, in particular the transcortical reflex hypothesis, which postulates the existence of reflex arcs in which "the cortico-motoneuronal projection is the efferent limb" (Phillips, 1969). Phillips' original concept, which was part of an appraisal of the motor apparatus of the primate hand, was fostered by the results of studies of the activity of pyramidal cells in motor cortex of awake monkeys (Evarts, 1967). Changes in the firing of these cells preceded voluntary movements and varied with the load impeding the voluntary movement in a manner apparently appropriate to compensate for the load. Other studies had shown that motor cortical stimulation could increase muscle tension through motor unit recruitment during imposed stretch of the muscle and thereby augment spinal stretch reflex activity in the baboon's hand (Phillips, 1969). On the basis of these results, Phillips proposed that transcortical reflexes could function in automatic compensation for unexpected loads in distal muscles of the primate forelimb (Phillips, 1970). The 
hypothesis that long latency EMG activity is produced by transmission through a transcortical reflex pathway was subsequently advanced by Evarts (1973) and by Marsden el al. (1973).

Partial, although indirect and conflicting, support for this hypothesis came from studies of the latency of M2 activity in different muscles, from lesion studies, and from studies of single motor cortical neurons in relation to peripheral EMG. These latency studies assumed that long latency activity in all muscles was produced by a common mechanism (Marsden et al., 1976; Watt et al., 1971; Chan et al., 1979). The demonstration of a correlation between latency of M2 onset in a muscle and length of the central conduction pathways to and from the motor cortex appeared consistent with the proposal. For example, the onset of M2 activity occurred later in muscles of the leg than in muscles of the arm, as predicted by the hypothesis. Within muscles of the forearm the latency of M2 activity would be predicted to vary with peripheral conduction time, because the central conduction distances are approximately the same for all muscles. However, the latency of M2 activity does not co-vary with the distance of the muscle from the spinal cord in the upper limb of squirrel monkeys (Lenz et al., 1983). Therefore, the latency data do not consistently support a common central mechanism for M2 reflex activity in all muscles of the primate forclimb.

Alteration of long latency reflex activity after lesions of structures in the proposed transcortical loop is not adequate to prove the hypothesis (Tatton et al., 1975), although it is an essential corollary. The early studies of humans with lesions of cortex and internal capsule (Lee and Tatton, 1975; Marsden et al., 1977b), dorsal columns (Marsden et al., 1977a; Lee and Tatton, 1978), cerebellum (Marsden et al., 1977c), and in monkeys with lesions of somatosensory cortex (Tatton et al., 1975) reported decreased, delayed, or absent long latency reflex activity. In contrast, Ghez and Shinoda (1978) demonstrated that long latency reflex activity in cat triceps remained unchanged after decerebration and spinalization. Similar findings were subsequently reported in primate biceps (Miller and Brooks, 1981) and triceps (Tracey et al., 1980), indicating that supraspinal pathways are not essential for long latency reflex activity in those muscles.

Motor cortical studies have examined both motor cortical unit and EMG activities with respect to relative timing (Evarts, 1973; Conrad et al., 1974; Tatton et al., 1978), the effect of voluntary "set" on these two activities (Evarts and Tanji, 1976), and the correlation of these two activities during imposed displacement (Cheney and Fetz, 1978; Bawa et al., 1979). The latency studies performed in primates have shown that the alteration of motor cortical unit firing activity produced by imposed joint displacement occurs at a latency which is compatible with these units producing the subsequent M2 response. In contrast, the only study performed in cat motor cortex found that the motor cortical activity occurs too early to contribute to the second burst of triceps EMG activity in this species (North and Tatton, 1980).

The companion paper (Lenz et al., 1983) has demonstrated significant differences in the EMG response of proximal and distal forelimb muscles to imposed joint displacement in normal animals. The present study was performed to determine whether the difference in the proximal-distal reflex patterns extended to lesioned animals. In performing this study we have attempted to overcome two critical methodological deficiencies which limit the interpretation of previous lesion studies. In previous studies, a single average measure of EMG activity at one torque load was used without control of base line EMG levels. This technique is limited by a large inherent experimental variability (see Tatton and Bawa (1979) for detailed discussion). In the present study, the EMG response is determined at several imposed torque load perturbations to the limb. This method provides an indicator of reflex "gain," which is a more reproducible measure of reflex function than the isolated measurement of reflex activity at one torque load (Gottleib and Agarwal, 1979; Tatton and Bawa, 1979). The second deficiency concerns the use of uncalibrated measures of EMG activity for comparisons within and between subjects. The approach adopted in this study has been to standardize the EMG output generated by torque motor-imposed joint displacement to a measure of maximum motor neuron output (Dietrichson, 1973; Tatton and Bedingham, 1981).

\section{Materials and Methods}

The present studies were performed over a period of 1 year on four adult male squirrel monkeys (Saimiri sciureus) weighing between 900 and $1200 \mathrm{gm}$.

Operative procedures. Anesthesia was induced with ketamine hydrochloride $(15 \mathrm{mg} / \mathrm{kg}$, i.m.) and atropine. Following endotracheal intubation, the animal was ventilated with a $\mathrm{O}_{2} / \mathrm{N}_{2} \mathrm{O}$-halothane mixture. Local anesthetic (Marcaine-bupivacaine hydrochloride, 0.75\%) was infiltrated bilaterally to produce a ring block of the external ear. The animal was then placed in a stereotactic frame and maintained on intravenous fluids. A craniectomy was performed from the midline laterally to the Sylvian fissure from the central sulcus anteriorly to the inferior arcuate sulcus. The exposed cortical surface was bathed with a warm artificial cerebrospinal fluid (CSF) solution. Excess CSF, which might cause current spread during stimulation, was removed by cotton wicks placed in the dependent region of the craniectomy. Forelimb motor cortex was mapped by anodal surface stimulation with a silver ball electrode. A 100 -msec train of $1.0-\mathrm{msec}$ square wave pulses at $300 \mathrm{~Hz}$ was used to drive a constant current stimulus isolator at levels of less than $400 \mu \mathrm{A}$. The response to stimulation was monitored visually and in two animals by EMG recordings. After comparison with cytoarchitectonic maps for this species (Rosabal, 1967; Sanides, 1968), areas of motor cortex from which forelimb movements were evoked were ablated together with a 1.0-mm margin by the method of subpial aspiration, with the aid of an operating microscope.

Assessment of lesioned monkeys. Reflex responses were studied in one proximal muscle, short head of biceps, and one distal muscle, flexor digitorum profundus, because these muscles showed different reflex responses characteristic of proximal and distal forelimb muscles and because the peaks of EMG activity in these muscles clearly do not have the same period as tension oscillations 
occurring during the imposed displacement (cf. Hagbarth et al., 1981; Lenz et al., 1983).

The methods of producing joint movement and recording EMG are as described in the companion paper (Lenz et al., 1983). The absolute amount of EMG activity produced at a number of different torque loads has been measured in this study. Reflex output has been plotted against torque input as a measure of the magnitude of the perturbation evoking reflex output (Tatton and Bawa, 1979). Initial velocity and maximal velocity of the displacements have been found to vary almost linearly with the imposed torque provided stiffness of the musclejoint systcm remains relativcly constant (sce "Results" and Tatton and Bawa, 1979; Tatton and Bedingham, 1981). The reflex responses were compared with a measure of maximum motor neuron output, the $\mathbf{M}$ response, which is the maximum EMG response evoked in a muscle by single, electrical stimulus to the nerve innervating the muscle (Magladery and Macdougal, 1950). The reflex and $\mathbf{M}$ responses are not strictly comparable because the $\mathbf{M}$ response is produced by synchronous motor neuron activation whereas the reflex response is produced by distributed motor neuron activation. Subject to this constraint, the comparison allows us to express the EMG response as a fraction of the maximal EMG response of motor neurons recorded by the electrodes. Background EMG level was also expressed as a fraction of the M response (less than $4 \%$ of the $M$ response in all muscles studied). The background EMG level is used as a measure of motor unit activity prior to the step load, which is an important determinant of reflex activity (Gottleib and Agarwal, 1979; Tatton and Bawa, 1979; Tatton and Bedingham, 1981). The $M$ response was evoked by transcutaneous stimulation of the motor nerve under ketamine sedation $(8 \mathrm{mg} / \mathrm{kg})$ at the conclusion of each session of reflex testing. In the case of FDP, the ulnar and median nerves were stimulated at the medial aspect of the upper arm. The $M$ response in biceps was obtained by stimulation of the musculocutaneous nerve just proximal to the insertion of pectoralis major. The intensity of the stimulus was increased until the response was observed to be maximal.

Histology. At the conclusion of these experiments, animals were given an overdose of pentobarbital and perfused with saline followed by $10 \%$ formalin in buffered saline. The brains were then photographed, blocked, and sectioned at $35 \mu \mathrm{m}$. Every 24 th section was mounted and stained with cresyl violet. Cytoarchitectonic areas were identified by the criterion of Brodmann $(1905,1912)$. The cytoarchitecture of areas 3 and 4 is unambiguously de-
A

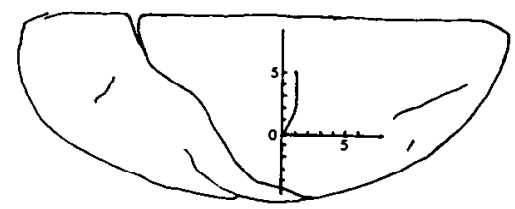

B

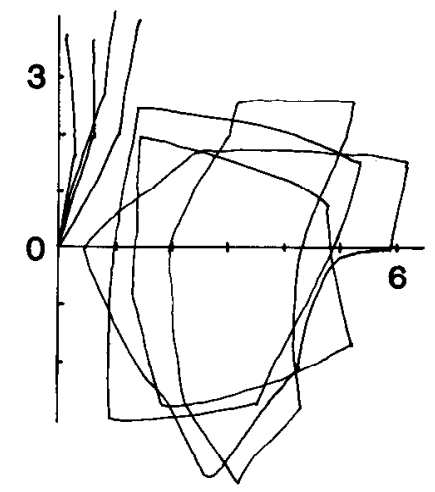

C

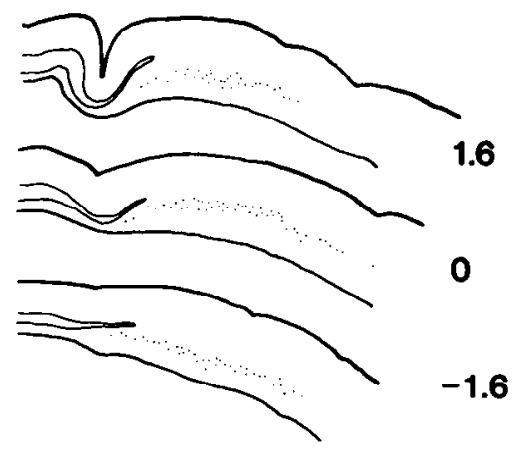

D

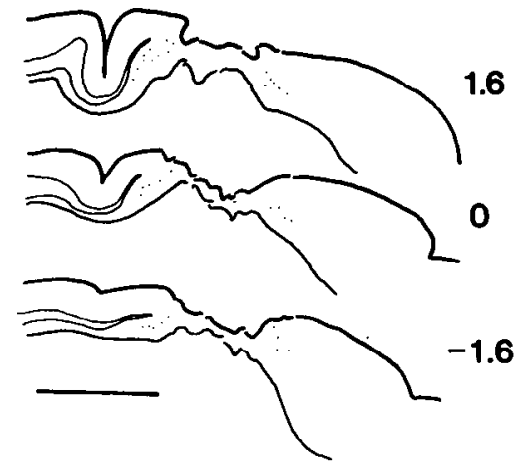

Figure 1. Extent of the area 4 (forelimb motor cortex) decortication. $A$ shows the right cortical surface of a normal squirrel monkey. The coordinate axis is aligned parrallel to the longitudinal sulcus, with zero at the most lateral extent of the central sulcus. The location of the motor cortical ablation and the central sulcus in four monkeys with reference to this coordinate system is shown in $B$. Camera lucida drawings of saggital sections through the cortex in the region of the central sulcus at mediolateral coordinates of $-1.6,0$, and $+1.6 \mathrm{~mm}$ are shown for a normal hemisphere and decorticate hemisphere in $C$ and $D$, respectively. In $C$ and $D$, the fine stipple shows the location of giant pyramidal cell somas, and the fine line encloses the extent of the granular cell layers. Axes are in millimeters, and the calibration bar in $\nu$ is $5 \mathrm{~mm}$. 
fined as granular and agranular cortex, respectively. However the distinction between these two areas is blurred at cortical area $3 \mathrm{~A}$, the transitional zone between areas 3 and 4 . This region is characterized by allenuation of the granular layers which, in new world primates, are overlapped by the giant pyramidal layer throughout the medial lateral extent of area $3 \mathrm{~A}$ (see Jones and Porter, 1980). In the present study the border between areas 3 and 4 was defined as the anterior extent of the attenuated granular cell layer on the basis of recent studies showing that this is (1) the posterior border of cortex where low threshold surface stimulation (Hore et al., 1976) and intracortical stimulation evoke peripheral movement (Strick and Preston, 1978; Sessle and Weisendanger, $1982)$; (2) the anterior limit of deep muscle receptor input to cortex (Jones et al., 1978; Jones and Porter, 1980); (3)
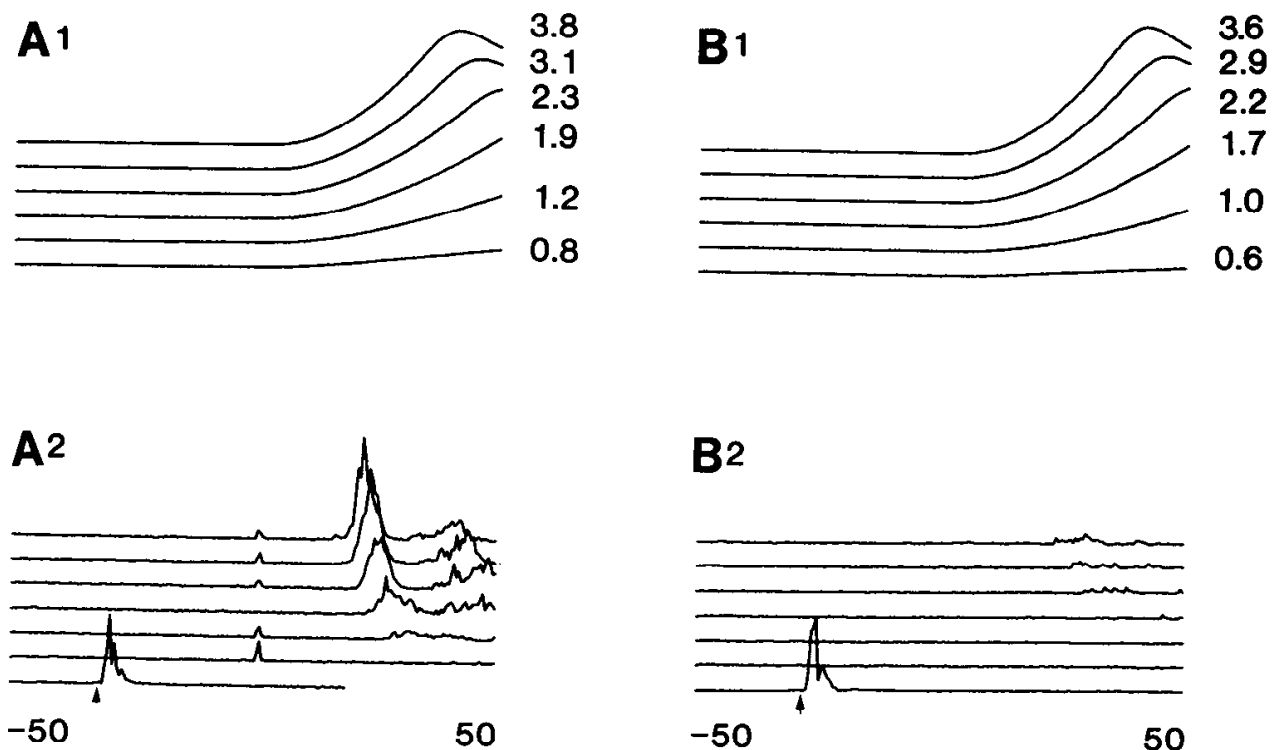

$\mathbf{B 2}$
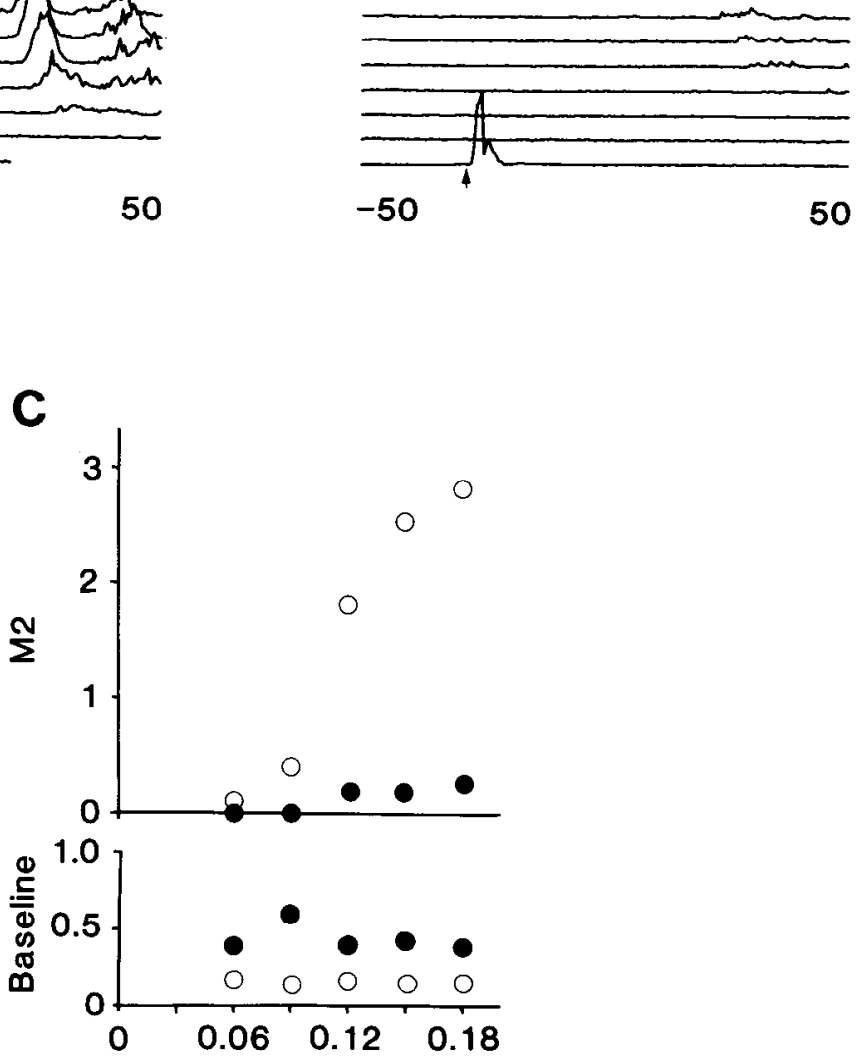

Torque Load (Nm)

Figure 2. FDP EMG response to MCP joint displacement in the unilateral area 4 decorticate monkey (M-21). $A 1$ and $A 2$ are for FDP ipsilateral to the cortical lesion, and $B 1$ and $B 2$ are for the contralateral muscle. $A I$ and $B I$ show the average imposed MCP joint displacements in response to six different torque loads. The numbers to the right of the displacement traces indicate the displacement in degrees over the first $15 \mathrm{msec}$, i.e., before any alterations in EMG activity occur. The corresponding EMG response to these displacements is displayed in the top six traces of $A 2$ and $B 2$. The seventh trace in $A 2$ is the maximal M response to stimulation of the ulnar and median nerves in the upper limb (arrow is at stimulus off and these traces are scaled to $1 / 100$ of those above). The area under the EMG response above buse line is expressed as a percentage of the integrated $M$ response and plotted against the torque load in $C$ (open circles represent the ipsilateral side and solid circles represent the contralateral side). The lower plot in $C$ is the base line EMG level, expressed as a percentage of the average height of the integrated $M$ response, for each point on the upper graph. 

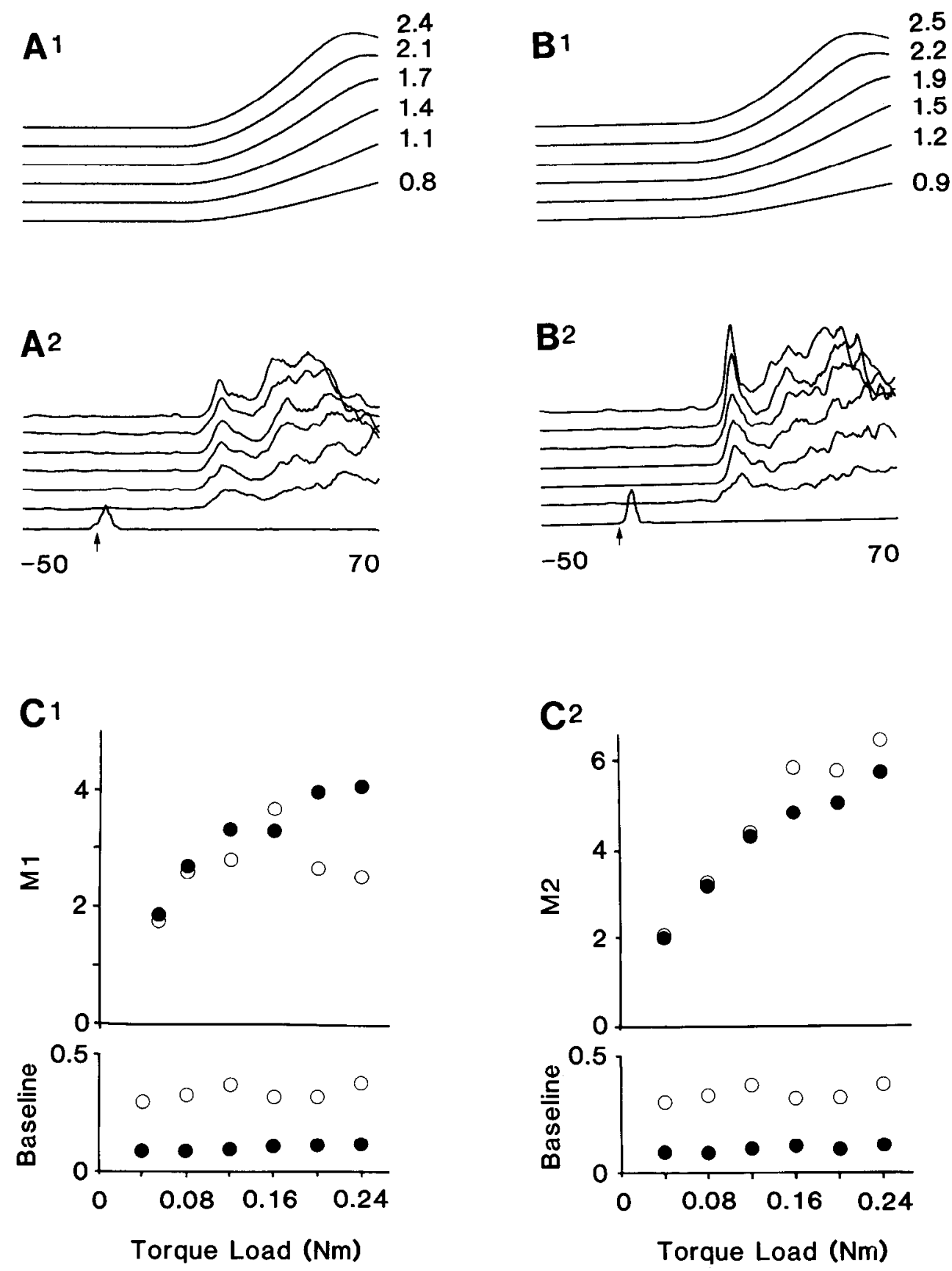

Figure 3. SHB EMG response to elbow extension in a unilateral area $4 \mathrm{~B}$ decorticate monkey (M-18). Conventions are as for Figure 2. $C 1$ and $C 2$ are plots for the M1 and M2 activity, respectively.

the anterior limit of projections to cortical area $3 \mathrm{~A}$ from VPLc, the thalamic relay nucleus for muscle receptor input (Friedman and Jones, 1981; Maendly et al., 1981).

\section{Results}

The extent of the lesions is shown in Figure 1. Figure $1 A$ shows the orientation of the rectangular coordinate system with respect to the central sulcus. Figure $1 B$ shows the extent of the lesion with respect to this coordinate system for the animals. For comparison with this map, Figure $1 C$ illustrates the extent of the giant pyramidal cell layer and the granular cell layers in the cortex of a normal hemisphere, at the medial lateral coordinates indicated. Note that the lesions in Figure $1 B$ stop anterior to the attenuated granular cell layer estimated from Figure $1 C$. This was histologically confirmed in the contralateral lesioned cortex, as demonstrated in Figure $1 D$. The histology was similar in the other three animals studied. Note that a margin of layer $\mathrm{V}$ pyramidal cells was preserved both anterior and posterior to the lesions. In summary, the lesions were limited to within the confines of cytoarchitectonic area 4 in the forelimb territory and did not extend into adjacent areas.

Postoperatively, animals had pronounced weakness of the forelimb contralateral to the ablation. The weakness resolved within 1 month so that the limb could be used effectively in running and climbing. However, a deficit in manipulative ability remained, as evidenced by a pref- 
erence for the use of the hand ipsilateral to the lesion and clumsiness of the contralateral hand during grooming and feeding behaviors. The reflex responses to torque motor-generated joint displacement were studied in FDP and SHB. Between 2 and 4 months postoperatively, all animals were tested bilaterally with determination of the $M$ response. Ipsilateral and contralateral limbs were studied on separate days because sedation for the $M$ response might interfere with subsequent testing on the same day.

Representative FDP reflex results for both sides of one lesioned animal with the accompanying $M$ responses are shown in Figure 2. The M2 peak is decreased and delayed on the side contralateral to the cortical lesion (the basis for identifying the peak as M2 is given in the companion paper, Lenz et al., 1983). Plots of reflex "gain" were constructed by graphing the area under the averaged, rectified EMG above base line against the torque load. The data in Figure 2, $A$ and $B$ for limbs ipsilateral and contralateral to the lesion have been displayed in such a plot in Figure 2C. The base line EMG levels shown below the gain plot demonstrate that the decrease in M2 response on the side contralateral to the lesion cannot be due to a decrease in base line EMG level, because the base line level is relatively increased on that side. Alternately, it could be argued that the increased base line EMG levels contralateral to the lesioned cortex resulted in increased stiffness and lower velocity displacements which evoked decreased EMG output. This was not the case, as illustrated by $A 1$ and $B 1$ in Figure 2, because the same torques applied to either side resulted in almost identical average displacements on the two sides. All four animals showed decreased M2 activity in FDP on the side contralateral to the lesion. A three-way analysis of variance with a co-variate factor, base line EMG, was performed on these data by individual monkey, limb, and torque level. The base line EMG did not co-vary with M2 activity $(F=0.08, d f=1, p<0.8)$, but there was a significant difference between limbs ipsilateral and contralateral to the lesion $(F=7.60, d f=1, p<0.01)$. Data from the "normal" side of these animals were compared with the same data from five unoperated animals and were found not to be significantly different (tested by a Generalized Mixed Model ANOVA-BMDPV2 because the data were nested within the experiment; i.e., separate groups of monkeys were used). The onset of EMG activity on the lesioned side was delayed contralateral to the lesion in some animals, but this was a variable finding (mean onset latency $22 \pm 5 \mathrm{msec}, n=18$ ) not significantly different from the contralateral side (mean $20 \pm 3 \mathrm{msec}$, $n=18$ ) or normal animals (mean $19 \pm 2 \mathrm{msec}, n=37$ ).

The corresponding results for the SHB reflex are shown in Figure 3. Note that there is a much less striking change in the M1 and M2 reflexes of SHB, shown in Figure $3, B$ and $C$, than in the FDP M2 reflex, shown in Figure 2. Statistical analysis of these results in four animals demonstrated a significant difference in M1 activity between the limbs $(F=4.26, d f=1, p<0.05)$. SHB M2 activity was found not be significantly different between limbs $(F=2.51, d f=1, p<0.20)$. Base line EMG was not a significant co-variate factor with either M1 or M2 activity in SHB. Highly significant interindividual variation was found both in SHB and in FDP.
In an attempt to display the pooled data from all four lesioned animals, the results for each animal were normalized to the largest EMG response occurring in the muscles on either side, combined and analyzed for each different imposed torque load. Base line levels have been similarly normalized to the maximal level and averaged. These results are shown for FDP M2 in Figure 4. Note that the long latency reflex activity occurring in FDP contralateral to the lesion is less, on the average, than that on the ipsilateral side. The corresponding results for SHB M1 and M2 are shown in Figure 5, $A$ and $B$. It can be seen that M1 activity is increased in biceps on the side contralateral to the cortical lesion at the highest torque loads, but M2 activity is the same on both sides. Inasmuch as average base line EMG levels are higher on the side ipsilateral to the lesion than on the contralateral side it could be argued that M2 activity might be significantly decreased on the contralateral side if base line levels were the same on both sides. However, the data do not support this contention bccause reflex levels did not co-vary with base line EMG in a statistically significant way $(F=0.06, d f=1, p<0.45)$. Furthermore, M2 activity was greater contralateral to the lesion in one of the two animals in which base line EMG was greater on that side. Therefore, although a significant cortical dependency for
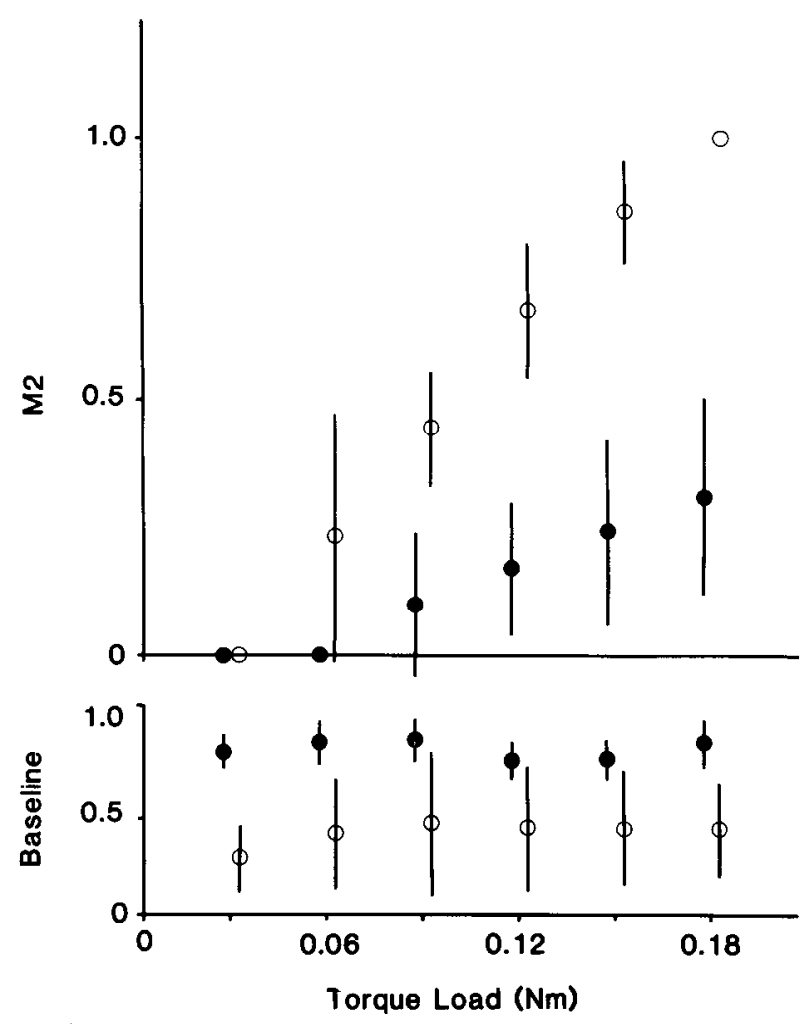

Figure 4. Averaged, normalized, FDP M2 response in the unilateral area 4 decorticate monkeys. The M2 responses on both sides of each monkey have been divided by the largest response occurring on either side. Results for ipsilateral and contralateral sides of all monkeys have been averaged at each torque load and plotted against torque load. Solid circles are the limbs contralateral to the lesion, and open circles are the ipsilateral side. Error bars are \pm 1 SD. Points without error bars occurred when all four values were identically 1 or 0 . 
A
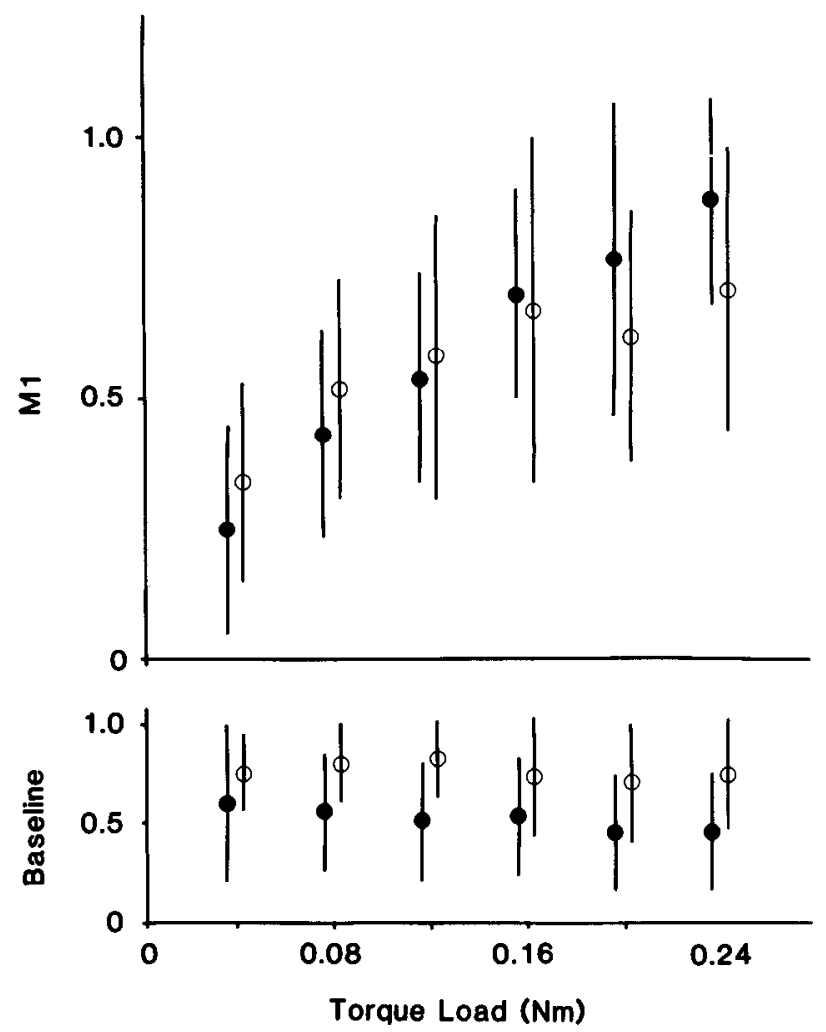

B


Figure 5. Averaged, normalized SHB M1 $(A)$ and M2 $(B)$ responses in the unilateral area 4 decorticate monkey. M1 and M2 responses for SHB have been treated separately as described in Figure 4.
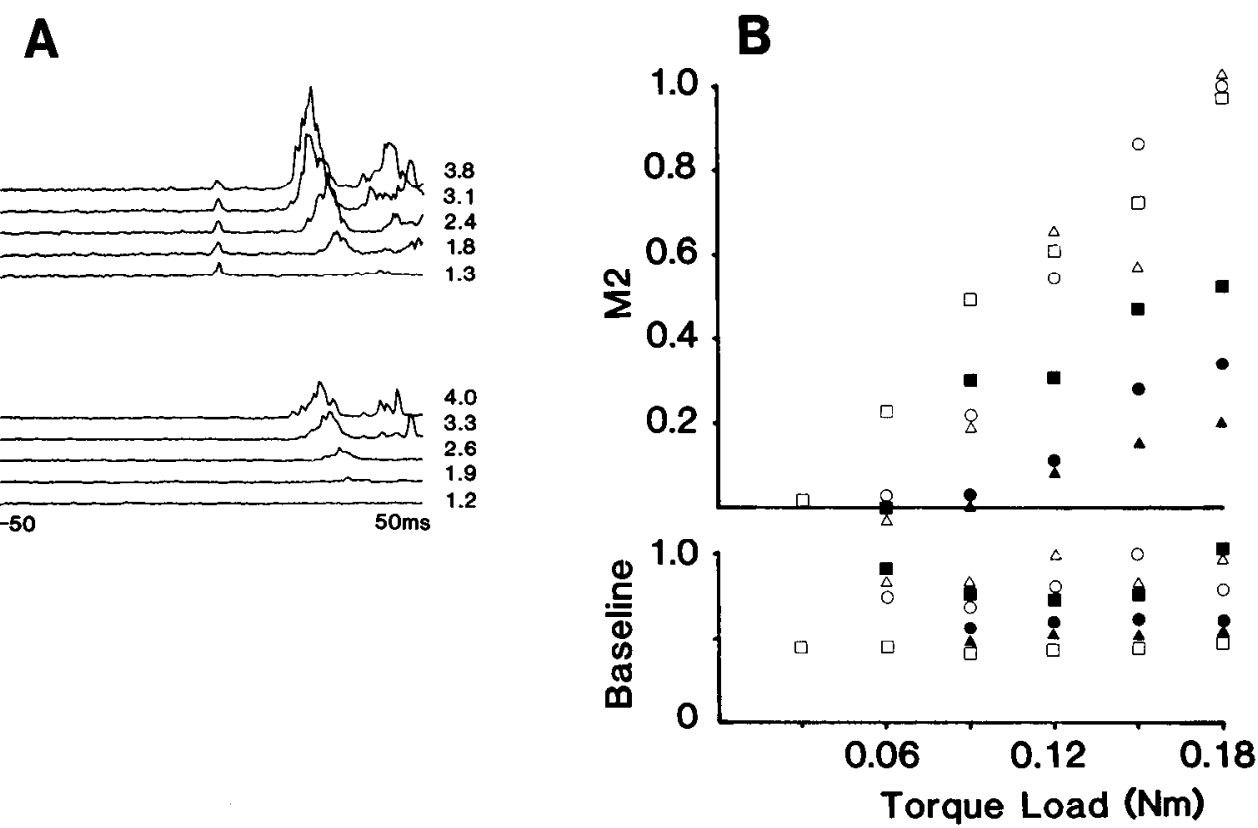

Figure 6. FDP responses in ipsilateral and contralateral limbs performed sequentially at the same recording session for three animals (each animal represented by a different symbol in $B$ ). A shows EMG records for the sides ipsilateral (upper) and contralateral (lower) to the lesion. The area, above base line, under the M2 peaks in these records has been normalized to the largest response occurring on either side and plotted against torque load in $B$.

SHB seems most unlikely in view of our data, it cannot be unequivocally excluded.

We performed two more tests in order to confirm the decrease in FDP activity contralateral to the lesion. As mentioned above, $M$ response normalization of reflex activity required that the two sides be tested on different days, because it was necessary to sedate the animals for the $M$ response. Therefore, testing was performed on 


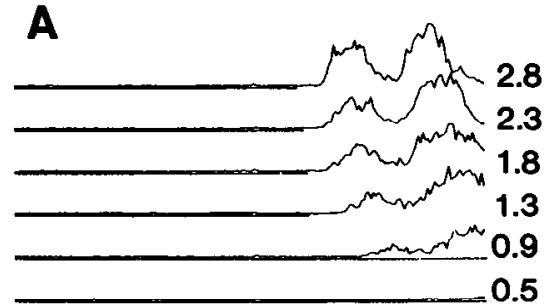

B


\section{C}

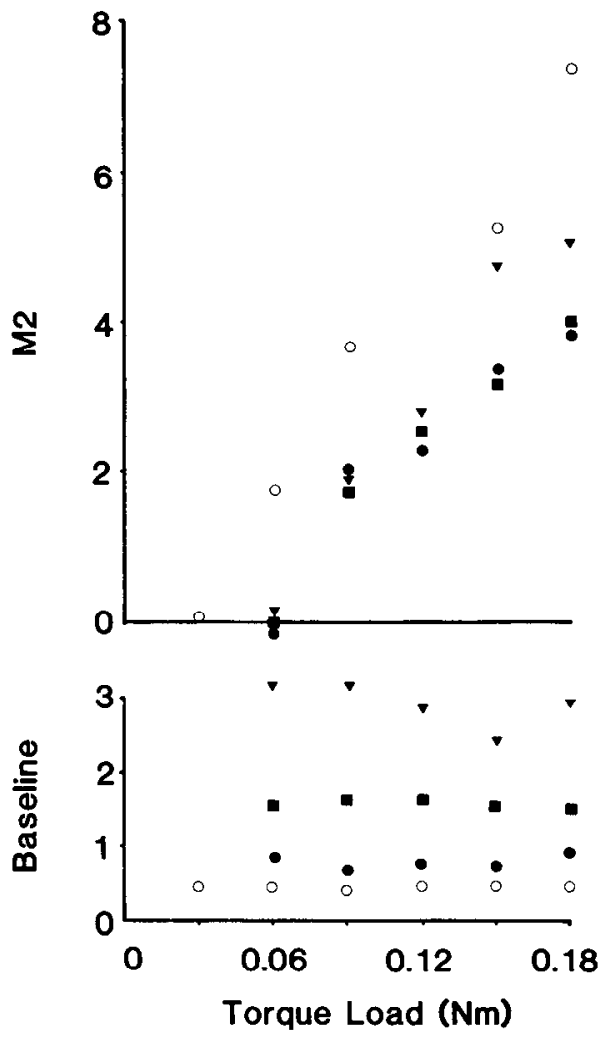

Figure 7. FDP responses at high tonic EMG levels contralateral to the lesion. $A$ shows the EMG response in the ipsilateral limb. The reflex responses to five different torque loads at three different base line EMG levels are shown for the contralateral limb in $B$. These results are plotted in arbitrary units in $C$.

both sides of the same animal on the same day, with all other factors held constant. $M$ responses were not performed. The results obtained in these trials, of which three are shown in Figure 6, demonstrated that there was a decrease in M2 activity on the contralateral side in comparison with the ipsilateral side.

The decrease in biceps M2 activity following central nervous system lesions has been reported to be simply the result of decreased base line EMG levels (Miller and Brooks, 1981). This seems unlikely in the case of FDP M2, because base line EMG did not co-vary significantly with M2 and because the higher average base line EMG contralateral to the lesion was associated with lower reflex activity. The effect of base line EMG level on reflex response was further examined by performing averages of events with high base line EMG levels on the side contralateral to the lesion. In none of the animals so tested did the reflex response at high base line EMG levels contralateral to the lesion exceed the response on the ipsilateral side. An example of this type of test, shown in Figure 7, demonstrates that M2 contralateral to the lesion does not exceed that on the side ipsilateral to the lesion even at base line EMG levels which are 6 times those on the ipsilateral side.

Note that, at similar background EMG levels, the magnitude of M2 activity normalized to the $\mathrm{M}$ response in normal SHB (Fig. 3) is twice that found in FDP (Fig. 2) in spite of the fact that the initial velocities achieved in SHB are two-thirds of those in FDP. Hence, the gain of reflex activity in SHB is 3 to 4 times greater than in FDP. This trend has been confirmed in 10 animals and is another example of the variation in reflex function between different muscles of the primate forelimb (Lenz et al., 1982).

\section{Discussion}

This study shows that FDP M2 activity is selectively and significantly decreased contralateral to a lesion of forelimb motor cortex. The decrease is not correlated with a decrease in base line EMG activity. M2 activity in SHB, on the other hand, was not detectably decreased contralateral to the cortical ablation. Unlike monkeys with MCA occlusion (Lenz et al., 1981a), monkeys with cortical lesions did not show increased FDP M1 activity. SHB M1 activity was slightly but significantly increased contralateral to the lesion. These results indicate that M2 activity is more dependent on the integrity of cortical structures in muscles acting across the hand than in more proximal muscles.

As explained in the introduction, there is variation in the reported results of previous lesion studies on EMG responses generated by different methods and in different 
TABLE I

Results of previous studies of the effect of lesions on M2 latency EMG activity

This table gives the muscle and species in which M2 activity was studied and the reported effect of the indicated central nervous system lesion on M2 activity in that muscle.

\begin{tabular}{|c|c|c|c|c|}
\hline Species & Muscle & Lesion & M2 & Author \\
\hline \multirow[t]{3}{*}{ Human } & FPL $L^{a}$ & Capsular & Absent or decreased & Marsden et al. (1977b) \\
\hline & & Sensorimotor cortex & Absent or decreased & Marsden et al. (1977b) \\
\hline & & Dorsal column & Absent & Marsden et al. (1977a) \\
\hline & & Sensorimotor cortex & Absent & Lee and Tatton (1978) \\
\hline & & Dorsal column & Absent & Lee and Tatton (1975) \\
\hline Cebus & Biceps & $\begin{array}{l}\text { Cortex, thalamus, } \\
\text { decerebrate, spin- } \\
\text { alized }\end{array}$ & Present & Miller and Brooks (1981) \\
\hline Macaca fascicularis & Triceps & Spinalized & Present & Tracey et al. (1980) \\
\hline Cat & Triceps & Intercol decerebrate & Present & Ghez and Shinoda (1978) \\
\hline Macaca speciosa & Triceps & Sensory cortex & Absent & Tatton et al. (1975) \\
\hline
\end{tabular}

${ }^{a}$ FPL, flexor pollicis longus.

muscles and species. However, in none of the previous lesion studies (Tatton et al., 1975, for example) has EMG activity been normalized to a measure of maximal EMG output (for example, $M$ response or maximal contraction); neither have they examined reflex "gain" by comparing the EMG responses to a number of different loads. It is possible that the large variation inherent in such uncalibrated measures of EMG activity at one torque load is a significant factor in explaining the different effects of CNS lesions on M2 activity reported in those studies. However, when the results of published lesion studies are examined by muscle group (see Table I), it can be seen that decreased long latency activity has been reported in every study of muscles acting across the primate wrist and hand but that results are variable in more proximal muscles. Although we have only examined a proximal and distal flexor muscle, there may also be differences in the cortical dependency of extensor as compared to flexor muscles acting across the same joint. For example, gastrocnemius and tibialis anterior show markedly different responses at the ankle (Gottlieb and Agarwal, 1979). Therefore, the variation in reported effects of CNS lesions on M2 activity could also be explained by differences in the muscle group studied.

Another possible source of variation in the results of lesion studies is the extent of the lesion. Maps of motor cortex derived from stimulation may be altered by the anesthetic and the stimulation technique. Hence, it is possible that the present lesions did not include all cortical areas efferent to the proximal forelimb muscles. However, evidence from studies which used uncalibrated EMG and single torque loads suggests that biceps M2 aclivily can be unaffected by extensive bilateral decortications which clearly include the proximal forelimb area (Miller and Brooks, 1981).

Experimental evidence from several sources demonstrates a preferential influence of motor cortex on distal musculature and anticipates the selective effect of motor cortical ablation found in this study. Anatomical data from different primates (Lui and Chambers, 1964; Petras, 1968; Kuypers, 1981) demonstrate a selective distribution of corticospinal terminals in the motor nuclei of distal muscles within the anterior horn (Rexed's lamina IX).
Electrophysiological data confirm the presence of a monosynaptic cortico-motoneuronal connection in primate forelimb muscles (Landgren et al., 1962; Fetz et al., 1976), especially in distal forelimb muscles (Phillips and Porter, 1964; Clough et al., 1968). Finally, behavioral studies of animals with lesions of the corticospinal tract (Brooks and Stoney, 1971; see Hepp-Reymond et al., 1974, reviewed by Asanuma, 1981) demonstrate a deficit limited to precision movements of the hand and digits. Therefore, the selective effect of motor cortical lesions on reflexes in FDP may be related to the greater functional dependency of primate distal limb musculature on cortical output.

The mechanism of FDP M2 cortical dependency cannot be determined from the results of this study (see Tatton et al., 1975). On the basis of other evidence, the two most likely mechanisms are loss of cortical facilitation of a segmental reflex or direct interruption of a transcortical reflex pathway. The former mechanism supposes that M2 activity is mediated through polysynaptic spinal pathways which have been demonstrated by several workers (for example, Hultborn and Wigstrom, 1980). Therefore, it remains to be seen whether M2 latency activity in FDP can be seen in hyperactive reflex states produced by supraspinal lesions such as decerebration or extensive bilateral decortication.

Although no lesion study can prove the direct participation of motor cortex in stretch reflexes, the present results indicate that, whatever the mechanism, M2 activity in distal musculature is partially dependent on an intact motor cortex. Motor cortical spike-triggered averages of EMG activity have demonstrated that the cortical response to imposed joint displacement is correlated with the M2 response (Cheney and Fetz, 1978). This finding indicates that cortical unit activity is linked to or shares common excitatory input with motor neurons giving rise to the M2 component. It does not prove that transcortical reflex arcs contribute directly to M2 activity, nor does it exclude other mechanisms which might make M2 activity dependent on the integrity of cortical structures. Equally, though, transcortical reflex arcs are not excluded as potentially significant contributors to long latency FMG activity in the distal musculature of the primate forelimb. 


\section{References}

Appelburg, B., H. Johansen, and G. Kalistratov (1977) The influence of group II muscle afferents and low threshold skin afferents on dynamic fusimotor neurons to the triceps surae of the cat. Brain Res. 132: 153-158.

Asanuma, H. (1981) The pyramidal tract. In Motor Control, Handbook of Physiology, V. B. Brooks, ed., Sect. 1, Vol. 2, Part 1, American Physiological Society, Bethesda, MD.

Bawa, P., and W. G. Tatton (1979) Motor unit responses in muscles stretched by imposed displacements of the monkey wrist. Exp. Brain Res. 37: 417-438.

Bawa, P., R. B. Stein, and W. G. Tatton (1979) Dynamics of the long latency pathway in the monkey. Biol. Cybern. 34: 107-110.

Brodmann, K. (1905) Beitrage zur histologischen lokalisation der Grosshirnrinde. 3. Mitteilung: Die Rindenfelder der Niederen Affen. J. Psychol. Neurol. 4: 177-226.

Brodmann, K. (1912) Neue ergebnisse uber die vergleichende histologische lokalisation der grosshirnrinde mit besonderer berucksichtigung des stirnhirns. Anat. Anz. (Suppl.) 41: 157216.

Brooks, V. B., and S. D. Stoney (1971) Motor mechanisms: The role of the pyramidal system in motor control. Annu. Rev. Physiol. 33: 337-392.

Chan, C. W. Y., G. Melvill-Jones, R. E. Kearney, and D. G. D. Watt (1979) The "late" electromyographic response to limb displacement in man. 1. Evidence for a supraspinal contribution. Electroencephalogr. Clin. Neurophysiol. 46: 173-181.

Cheney, P. D., and E. E. Fetz (1978) Functional properties of primate corticomotoneuronal cells. Soc. Neurosci. Abstr. 4: 293.

Clough, J. F. M., D. Kernell, and C. G. Phillips (1968) The distribution of monosynaptic excitation from the pyramidal tract and from primary spindle afferents to motor neurons of the baboon's hand and forearm. J. Physiol. (Lond.) 198: 145166.

Conrad, B., K. Matsunami, J. Meyer-Lohmann, M. Weisendanger, and V. B. Brooks (1974) Cortical load compensation during voluntary elbow movements. Brain Res. 71: 507-514.

Dietrichson, P. (1973) The role of the fusimotor system in spasticity and parkinsonian rigidity. In New Developments in Electromyography and Clinical Neurophysiology, J. E. Desmedt, ed., Vol. 3, pp. 496-507, S. Karger, AG, Basel.

Evarts, E. V. (1967) Representation of movements and muscles by pyramidal tract neurons of the precentral motor cortex. In Neurophysiological Basis of Normal and Abnormal Motor Activities, M. D. Yahr and D. P. Purpura, eds., Raven Press, New York.

Evarts, E. V. (1973) Motor cortex reflexes associated with learned movement. Science 179: 501-503.

Evarts, E. V., and J. Tanji (1976) Reflex and intended responses in motor cortex pyramidal tract neurons of monkey. J. Neurophysiol. 39: 1069-1080.

Fetz, E. E., P. D. Cheney, and D. C. German (1976) Corticomotoneuronal connections of precentral cells detected by post spike averaging of EMG activity in behaving monkeys. Brain Res. 114: 505-510.

Friedman, D. P., and E. G. Jones (1981) Thalamic input to areas $3 a$ and 2 in monkeys. J. Neurophysiol. 45: 59-85.

Ghez, C., and Y. Shinoda (1978) Spinal mechanisms of the functional stretch reflex. Exp. Brain Res. 32: 55-68.

Gottlieb, G. L., and C. G. Agarwal (1979) Response to sudden torques about the ankle in man: Myotatic reflex. J. Neurophysiol. 42: 91-105.

Hagbarth, K. E., J. V. Hagglund, E. U. Wallin, and R. R. Young (1981) Grouped spindle and electromyographic responses to abrupt wrist extension movements in man. J. Physiol. (Lond.) 312: 81-96.
Hepp-Reymond, M.-C., E. Trouche, and M. Wiesendanger (1974) Effects of unilateral and bilateral pyramidotomy on conditioned rapid precision grip in monkeys (Macaca fascicularis). Exp. Brain Res. 21: 519-527.

Hore, J., J. B. Preston, R. G. Durkovic, and P. D. Cheney (1976) Responses of cortical neurons (areas 3a and 4) to ramp stretch of hindlimb muscles in the baboon. J. Neurophysiol. 39: 484500 .

Hultborn, H., and H. Wigstrom (1980) Motor responses with long latency and maintained duration evoked by activity in $1 \mathrm{~A}$ afferents. Prog. Clin. Neurophysiol. 8: 99-116.

Jones, E. G., and R. Porter (1980) What is area 3a? Brain Res. Rev. 203: 1-45.

Jones, E. G., J. D. Coulter, and S. H. C. Hendry (1978) Intracortical connectivity of architectonic fields in the somatic sensory, motor and parietal cortex of monkeys. J. Comp. Neurol. 181: 291-348.

Kuypers, H. G. J. M. (1981) Anatomy of descending pathways. In Motor Control, Handbook of Physiology, V. B. Brooks, ed., Sect. 1, Vol. 2, Part 1, American Physiological Society Bethesda, MD.

Landgren, S., C. G. Phillips, and R. Porter (1962) Minimal synaptic actions on some alpha motoneurons of the baboon's hand and forearm. J. Physiol: (Lond.) 161: 91-111.

Lee, R. G., and W. G. Tatton (1975) Motor responses to sudden limb displacements in primates with specific CNS lesions and in human patients with motor system disorders. Can. J. Neurol. Sci. 2: 285-293.

Lee, R. G., and W. G. Tatton (1978) Long loop reflexes in humans: Clinical application. Prog. Clin. Neurophysiol. 4: 334-341.

Lee, R. G., W. G. Tatton, F. E. Leblanc, and R. H. A. Haslam (1976) Long loop motor reflexes in spastic hemiplegia and in patients with cortical sensory loss. Can. J. Neurol. Sci. 3: 156.

Lenz, F. A., R. R. Tasker, and T. Tsuda (1981a) MCA occlusion in the squirrel monkey: Clinical picture and torque motor studies. Neurology (Minneap.) 30: 49.

Lenz, F. A., R. R. Tasker, and W. G. Tatton (1981b) 'The effect of cortical lesions on reflex responses to torque perturbations in the squirrel monkey forelimb. Soc. Neurosci. Abstr. 7: 560.

Lenz, F. A., S. Schloegel, W. G. Tatton, and R. R. Tasker (1982) Mechanical properties of the primate forelimb during imposed displacement. Soc. Neurosci. Abstr. 8: 535.

Lenz, F. A., W. G. Tatton, and R. R. Tasker (1983) Electromyographic response to displacement of different forelimb joints in the squirrel monkey. J. Neurosci. 3: 783-794.

Lui, C. N., and W. W. Chambers (1964) An experimental study of the corticospinal system in the monkey (Macaca mulatta): The spinal pathways and preterminal distribution of degenerating fibers following discrete lesions of the pre- and postcentral gyri and bulbar pyramid. J. Comp. Neurol. 123: 257283.

Maendly, R., D. G. Ruegg, M. Weisendanger, R. Weisendanger, J. Lagowska, and B. Hess (1981) Thalamic relay for group 1 muscle afferents of forelimb nerves in the monkey. J. Neurophysiol. 46: 901-917.

Magladery, J. W., and D. B. Macdougal (1950) Electrophysiological studies of nerve and muscle reflex activity in normal man. 1. Identification of certain reflexes in the electromyogram and the conduction velocity of peripheral nerve fibers. Bull. Johns Hopkins Hosp. 86: 265-290.

Marsden, C. D., P. A. Merton, and H. B. Morton (1973) Latency measurements compatible with a cortical pathway for the stretch reflex in man. J. Physiol. (Lond.) 230: 58-59.

Marsden, C. D., P. A. Merton, and H. B. Morton (1976) Stretch reflex and servo action in a variety of human muscles. J. Physiol. (Lond.) 259: 531-560.

Marsden, C. D., P. A. Merton, and H. B. Morton (1977a) The effect of posterior column lesions on servo responses from the 
human long thumb flexor. Brain 100: 185-200.

Marsden, C. D., P. A. Merton, H. B. Morton, and J. Adam (1977b) The effect of lesions of sensorimotor cortex and the capsular pathways on servo responses from the human long thumb flexor. Brain 100: 503-526.

Marsden, C. D., P. A. Merton, H. B. Morton, M. Hallett, J. Adam, and D. N. Rushton (1977c) Disorders of movement in cerebellar disease in man. In Physiological Aspects of Clinical Neurology, F. C. Rose, ed., Blackwell, Oxford.

Miller, A. D., and V. B. Brooks (1981) Late muscular responses to arm perturbations persist during supraspinal dysfunctions in monkeys. Exp. Brain Res. 41: 146-158.

North, A. E. G., and W. G. Tatton (1980) Temporal relations between motor cortical and FMG responses to imposed forelimb displacements in the cat. Soc. Neurosci. Abstr. 7: 392.

Petras, J. M. (1968) Corticospinal fibers in new world and old world simians. Brain Res. 8: 206-208.

Phillips, C. G. (1969) Motor apparatus of the baboon's hand. The Ferrier Lecture, 1968. Proc. R. Soc. Lond. (Biol.) 173: 141-174.

Phillips, C. G. (1970) Evolution of the corticospinal tract in primates with special reference to the hand. In Proceedings of the Third International Congress of Primatology, Vol. 2, pp. 2-23, S. Karger, AG, Basel.

Phillips, C. G., and R. Porter (1964) The pyramidal projection to motor neurons of some muscle groups of the baboon's forelimb. Prog. Brain Res. 12: 222-242.

Rosabal, F. (1967) Cytoarchitecture of the frontal lobe of the squirrel monkey. J. Comp. Neurol. 130: 87-108.

Sanides, F. (1968) The architecture of the cortical taste areas in the squirrel monkey (Saimiri scuireus) and their relationships to insular, sensorimotor and prefrontal regions. Brain Res. 8: 97-124.
Sessle, B. J., and M. Wiesendanger (1982) Structural and functional definition the motor cortex of the monkey (Macaca fascicularis). J. Physiol. (Lond.) 323: 245-265.

Stauffer, E. H., D. G. D. Watt, A. Taylor, A. M. Reinking, and E. G. Stuart (1976) Analysis of muscle receptor connections by spike triggered averaging. 2. Spindle group II afferents. J. Neurophysiol. 39: 1393-1402.

Strick, P. L., and J. B. Preston (1978) Multiple representation in the primate motor cortex. Brain Res. 154: 366-370.

Tatton, W. G., and P. Bawa (1979) Input-output properties of motor unit responses in muscles stretched by imposed displacement of the monkey wrist. Exp. Brain Res. 37: 439-457.

Tatton, W. G., and W. Bedingham (1981) Characteristic long latency reflex abnormalities in dystonia and rigidity. Can. Cong. Neurol. Sci. 16: 138.

Tatton, W. G., S. D. Forner, G. L. Gerstein, W. W. Chambers, and E. W. Lui (1975) The effect of post-central cortical lesions on motor responses to sudden upper limb displacements in monkeys. Brain Res. 196: 108-113.

Tatton, W. G., P. Bawa, I. C. Bruce, and R. G. Lee (1978) Longloop reflexes in monkeys: An interpretive base for human reflexes. Prog. Clin. Neurophysiol. 4: 229-245.

Tatton, W. G., P. Bawa, and I. C. Bruce (1979) Altered motor cortical activity in motor cortical rigidity. Adv. Neurol. 10: 141-160.

Tracey, D. J., B. Walmsley, and J. Brinkman (1980) "Long loop" reflexes can be obtained in spinal monkeys. Neuro. Litt. 18: 59-66.

Watt, D. G. D., C. W. Y. Chan, and G. Melville-Jones (1971) Is the late response to muscle stretch in man mediated through a long-loop reflex pathway? DRB Aviat. Med. Res. Unit. Rep. 3: 210-222. 